\title{
Coronavirus Disease 2019 (COVID-19)-Associated Hospitalization and Mortality in Patients with Psoriasis: A Population-Based Study
}

\author{
Khalaf Kridin ${ }^{1,2}$ (1) $\cdot$ Yochai Schonmann ${ }^{3} \cdot$ Dana Tzur Bitan $^{4} \cdot$ Giovanni Damiani $^{5} \cdot$ Alon Peretz $^{3} \cdot$ Orly Weinstein $^{3,6}$. \\ Arnon D. Cohen ${ }^{3,6}$
}

Accepted: 17 April 2021 / Published online: 31 May 2021

(c) The Author(s) 2021

\begin{abstract}
Background The impact of immune-related conditions on the outcomes of coronavirus disease 2019 (COVID-19) is poorly understood. Determinants of COVID-19 outcomes among patients with psoriasis are yet to be established.

Objective Th objective of this study was to characterize a large cohort of patients with psoriasis with COVID-19 and to identify predictors of COVID-19-associated hospitalization and mortality.

Methods A population-based nested case-control study was performed using the computerized database of Clalit Health Services, Israel. Multivariable logistic regression was used to estimate odds ratios (ORs) and 95\% confidence (CIs) of predictors for COVID-19-associated hospitalization and mortality.

Results The study population included 3151 patients with psoriasis who tested positive for COVID-19. Subclinical COVID19 infection occurred in 2818 (89.4\%) of the patients while $122(3.9 \%), 71(2.3 \%), 123(3.9 \%)$, and $16(0.5 \%)$ of the patients experienced a mild, moderate, severe, and critical disease, respectively. Overall, 332 (10.5\%) patients were hospitalized and $50(1.6 \%)$ patients died because of COVID-19 complications. Intake of methotrexate independently predicted COVID-19-associated hospitalization (adjusted OR 2.30; 95\% CI 1.11-4.78; $p=0.025$ ). Use of biologic agents was not associated with COVID-19-associated hospitalization (OR 0.75 ; 95\% CI $0.32-1.73 ; p=0.491$ ) or mortality (OR 0.85 ; 95\% CI $0.12-6.21$; $p=0.870$ ). Older age, the presence of comorbid cardiovascular diseases, metabolic syndrome, chronic obstructive pulmonary disease, and chronic renal failure independently predicted both COVID-19-associated hospitalization and mortality.

Conclusions The use of oral methotrexate was associated with an increased odds of COVID-associated hospitalization, whereas the use of biologic drugs was not associated with worse outcomes of COVID-19 among patients with psoriasis.
\end{abstract}

Orly Weinstein and Arnon D. Cohen contributed equally to the article.

Khalaf Kridin

dr_kridin@hotmail.com

1 Lübeck Institute of Experimental Dermatology, University of Lübeck, Ratzeburger Allee 160, 23562 Lübeck, Germany

2 Azrieli Faculty of Medicine, Bar-Ilan University, Safed, Israel

3 Clalit Health Services, Tel-Aviv, Israel

4 Department of Behavioral Sciences, Ariel University, Ariel, Israel

5 Clinical Dermatology, IRCCS Istituto Ortopedico Galeazzi, Milan, Italy

6 Faculty of Health Sciences, Ben-Gurion University of the Negev, Ben-Gurion Ave, Beer Sheva, Israel

\section{Key Points}

In patients with psoriasis, the use of oral methotrexate was associated with an increased COVID-associated hospitalization.

The administration of biologic drugs during the pandemic was not associated with COVID-associated hospitalizations or mortality.

Caution may be practiced in the utilization of methotrexate for psoriasis during the pandemic. 


\section{Introduction}

Coronavirus disease 2019 (COVID-19), caused by severe acute respiratory syndrome coronavirus 2 (SARS-CoV-2), embodies an unprecedented global health crisis with enormous social, mental, and financial ramifications [1]. Given that severe COVID-19 is associated with a hyperinflammatory state $[2,3]$, it is of interest to explore whether the presence of preexisting immune-mediated diseases or the previous use of immunomodulatory agents influences the phenotype of COVID-19. While several studies displayed an increased risk and a more aggressive course of SARSCoV-2 infection in patients with certain immune-mediated and autoimmune diseases [4-6], others refuted these observations [7-11].

Psoriasis is a chronic, immune-mediated, papulosquamous skin disease that affects 125 million people worldwide [12]. The disease is unequally distributed across geographical regions, and its prevalence rate ranges between $0.14 \%$ in East Asia and 1.99\% in Australia [13]. The typical psoriatic lesion is a sharply demarcated, erythematous scaly plaque commonly affecting the extensor surfaces, but it can also involve the intertriginous areas, palms, soles, and nails. Present in $20-30 \%$ of patients with psoriasis, psoriatic arthritis usually either follows or occurs concurrently with the cutaneous manifestation $[12,14]$.

The medical society struggles with major uncertainty regarding the optimal method to manage patients with immune-mediated diseases necessitating systemic drugs during the COVID-19 pandemic. As immunosuppressive therapy can interfere with antiviral immunity [15], patients undergoing immunomodulatory treatment, particularly those with severe comorbidities, may be hypothetically more susceptible to worse outcomes of COVID-19. In contrast, it has been postulated that over-activation of the immune system accounts for the lung injury caused by SARS-CoV-2 and that a subgroup of patients might benefit from immunosuppressive drugs [16]. The burden of COVID-19 and predictors of its complications among patients with psoriasis are yet to be fully delineated [17-19].

The aim of the current study is to characterize a large cohort of patients with psoriasis who tested positive for COVID-19. We additionally sought to identify determinants of COVID-19-associated hospitalization and mortality among these patients.

\section{Methods}

\subsection{Study Design and Dataset}

The current study was designed as a nested case-control study that followed all patients with psoriasis who tested positive for COVID-19. Predictors of COVID-associated hospitalization and mortality were systematically evaluated using a case-control design comparing patients with psoriasis with hospitalization and mortality relative to those lacking these outcomes. The study was approved by the institutional review board in accordance with the Declaration of Helsinki (approval code: 0212-17-COM).

The study was based on the computerized dataset of Clalit Health Services. Clalit Health Services is the largest health maintenance organization in Israel, which provides a wide array of private and public healthcare services for 4,603,861 enrollees as of February 2020. Clalit Health Services dataset enables comprehensive access to a wide range of clinical input as it retrieves data from several sources covering general community clinics, both primary care and referral centers, and both ambulatory and hospital care facilities. The inclusiveness, negligible loss to follow-up, and universal access to public healthcare services qualify the dataset to yield robust epidemiological studies [20].

\subsection{Study Population and Definition of COVID-19-Related Variables}

The computerized dataset of Clalit Health Services was systematically checked for prevalent cases with a diagnosis of psoriasis, as documented by a board-certified dermatologist. The medical records of these patients were checked for a diagnosis of COVID-19. The latter was based on confirmation of cases by a US Food and Drug Administrationapproved molecular test.

COVID-19-associated hospitalization was defined in COVID-19-confirmed patients admitted to intensive care units, internal medicine, or pulmonology inpatient wards. All hospitalized patients with COVID-19 were assigned one of the following severity degrees; mild (mild symptoms such as cough, fever, fatigue, and loss of smell); moderate (clinical or radiologic diagnosis of COVID-19 pneumonia); severe (respiratory rate $>30$, oxygen saturation $<93 \%$ on room air, and $\mathrm{PaO}_{2} / \mathrm{FiO}_{2}<300$ ); and critical (severe systemic impairment including septicemia, cardiac, hepatic, or renal insufficiency). The severity degree of non-hospitalized COVID-19-confirmed patients, who were not managed in any healthcare facility, was defined as subclinical.

Participants' date of death was ascertained by crosslinking the study cohort with the National Registry of 
Deaths Database. All study participants were followed up from the onset of the pandemic in Israel (defined as the date of the first confirmed case on 27 February, 2020), until 30 September, 2020 or death.

\subsection{Definition of Psoriasis-Related and Comorbidity Variables}

The severity of psoriasis was defined as moderate to severe in patients who were managed by oral systemic drugs (methotrexate, cyclosporine, apremilast, and acitretin), biologic agents (tumor necrosis factor- $\alpha$ inhibitors, interleukin [IL]17 inhibitors, IL-23 inhibitors, and ustekinumab), or phototherapeutic modalities (ultraviolet B, psoralen and ultraviolet A, and climate therapy in the Dead Sea) at any time point throughout the course of the disease. Patients who were not managed by any of the aforementioned interventions were considered as having mild disease.

Owing to the accumulation of evidence about the vulnerability of pharmacologically immunosuppressed patients with COVID-19 [15], we checked whether the intake of any biologic drug or the intake of oral-systemic drugs with immunosuppressive properties (methotrexate and cyclosporine) during or at the onset of the pandemic predicted worse COVID-19 outcomes. Exposure to a certain drug was defined in those purchasing a drug for at least 2 months during the pandemic. The diagnosis of psoriatic arthritis relied on its coding by a rheumatologist in a patient with an eligible diagnosis of psoriasis.

The chronic registry of Clalit Health Services was utilized to identify comorbidities of eligible patients prior to the development of COVID-19. Cardiovascular disease was defined as the presence of at least one of the following conditions: ischemic heart disease, a history of myocardial infection, congestive heart failure, or arrhythmia. Metabolic syndrome was defined as the presence of at least three of the following conditions: type 2 diabetes mellitus, dyslipidemia, hypertension, or obesity [21-23]. Study outcomes were additionally adjusted for chronic obstructive pulmonary disease (COPD), chronic renal failure (CRF), asthma, smoking, cirrhosis, malignancy, depression, and a history of tuberculosis.

\subsection{Statistical Analysis}

Baseline characteristics were described by means and standard deviations (SDs) for continuous variables, whilst categorical values were indicated by percentages. The comparison between patients with and without COVID19-associated hospitalization and mortality was performed utilizing the chi-square test and $t$-test for categorical and continuous variables, respectively.

Only comorbidities and medications preceding the onset of COVID-19 were included in the analyses based on the temporal relationship between exposure and outcome in case-control studies. The independent associations between demographic, disease-specific, and comorbidity variables with the odds of COVID-19-associated hospitalization and mortality were evaluated using multivariable-adjusted logistic regression and reported as odds ratios (ORs) and 95\% confidence intervals (CIs). Enter and removal limits were set at $p<0.050$ in the univariate analysis. The covariates included in the regression model encompassed, among others, age group and duration of psoriasis. The latter continuous variables were treated as dichotomous variables and split by their median value (44.0 and 7.6 years, respectively). Because of the significant co-linearity between them, the two following pairs of variables were collapsed as single variables in the regression model: (i) age at the onset of pandemic and the duration of psoriasis and (ii) disease severity and intake of oral systemic agents. Categories with cell sizes $<10$ by hospitalization and death status were collapsed to ensure sufficient power in the adjusted model. SPSS software, Version 25 (SPSS; IBM Corp; Armonk, NY, USA) was utilized to conduct all statistical analyses.

\section{Results}

\subsection{Characteristics of the Study Population}

The study population included 3151 patients with psoriasis who tested positive for COVID-19. The mean age (SD) of patients at the diagnosis of COVID-19 was 46.0 (19.3) years, $1656(52.6 \%)$ were male, 1935 (61.4\%) were of Jewish ethnicity, and 1416 (44.9\%) had low socioeconomic status (Table 1).

The mean (SD) age of patients at the onset of psoriasis was 38.2 (18.9) years, with an average (SD) latency of 7.8 years separating the onset of psoriasis and the development of COVID-19. In all, $2712(86.1 \%)$ patients had mild psoriasis, whereas 439 (13.9\%) manifested with moderateto-severe disease. Psoriatic arthritis was present in 708 $(22.5 \%)$ patients and flexural psoriasis in $804(25.5 \%)$ patients. While biologics were administered for 74 (2.3\%) patients at the onset of the pandemic, $86(2.7 \%)$ were taking oral systemic anti-psoriatic medications. Table 1 further elaborates on different therapeutic modalities utilized during the course of psoriasis and Table 1 of the Electronic Supplementary Material (ESM) on the main comorbid conditions of the study population. 
Table 1 Characteristics of study population

Characteristic

Patients with psoriasis and COVID-19 $(N=$

3151)

Demographic variables

Age at the diagnosis of COVID-19, years

Mean (SD)

$46.0(19.3)$

Median (range)

$44.0(2.3-97.8)$

Sex, $n(\%)$

Male

$1459(47.4)$

Female

$1656(52.6)$

Ethnicity, $n(\%)$

Jews

$1935(61.4)$

Arabs

870 (27.6)

Ultra-orthodox Jews

$346(11.0)$

Socioeconomic status, $n(\%)$

Low

$1416(44.9)$

Intermediate

1216 (38.6)

High

$509(16.2)$

Characteristics and treatment of psoriasis

Age at the onset of psoriasis, years

Mean (SD)

$38.2(18.9)$

Median (range)

$36.4(0.3-90.2)$

Duration of psoriasis at the diagnosis of COVID-19, years

Mean (SD)

$7.8(4.7)$

Median (range)

$7.6(0.2-18.1)$

Severity of psoriasis, $n(\%)$

Mild

$2712(86.1)$

Moderate to severe

439 (13.9)

Psoriatic arthritis, $n(\%)$

$708(22.5)$

Flexural psoriasis, $n(\%)$

$804(25.5)$

Biologics at the onset of pandemic, $n(\%)^{\mathrm{a}}$

$74(2.3)$

Oral systemic agents at the onset of pandemic, $n(\%)^{\mathrm{b}}$

$86(2.7)$

Biologics anytime during the course of psoriasis, $n(\%)^{\mathrm{a}}$

$89(2.8)$

Oral systemic agents anytime during the course of psoriasis, $n(\%)^{\mathrm{b}}$

$322(10.2)$

Phototherapy anytime during the course of psoriasis, $n(\%)^{\mathrm{c}}$

$210(6.7)$

The onset of the pandemic was defined as the date of the first confirmed case of COVID-19 in Israel 27 February, 2020

COVID-19 coronavirus disease 2019, SD standard deviation

${ }^{a}$ Tumor necrosis factor- $\alpha$ inhibitors, interleukin-17 inhibitors, interleukin-23 inhibitors, and ustekinumab

${ }^{\mathrm{b}}$ Methotrexate, cyclosporine, apremilast, and acitretin

${ }^{\mathrm{c}}$ Ultraviolet B, psoralen and ultraviolet A, and climate therapy in the Dead Sea

\subsection{Characteristics of COVID-19 Among Patients with Psoriasis}

While the vast majority of patients $(n=2819 ; 89.4 \%)$ presented with subclinical COVID-19 infection, 122 (3.9\%), 71 $(2.3 \%), 123(3.9 \%)$, and $16(0.5 \%)$ patients experienced a mild, moderate, severe, and critical disease, respectively (Fig. 1). Overall, $332(10.5 \%)$ patients were hospitalized because of COVID-19 complications, and 33 (1.1\%) patients underwent mechanical ventilation. The mean (SD) length of hospitalization was estimated at 8.3 (10.6) days. Fifty-one (1.6\%) patients died following COVID-19 infection, all of whom were hospitalized prior to their death. 

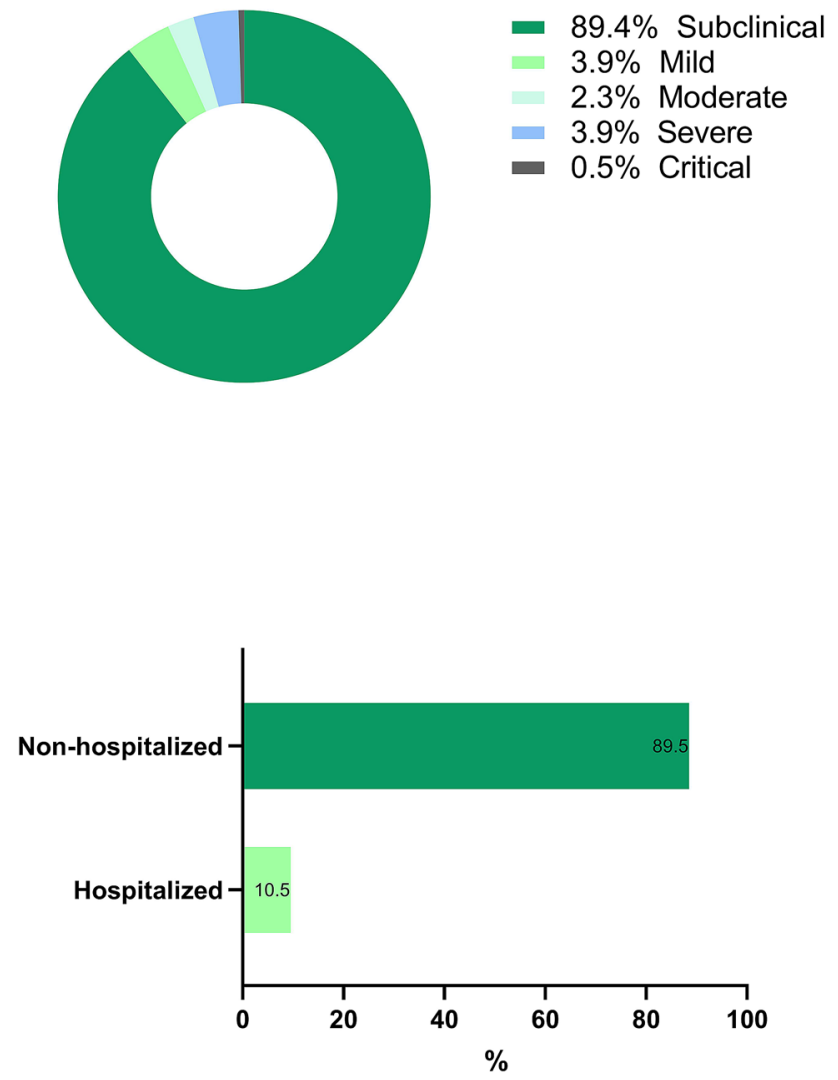

Fig. 1 Distribution of COVID-19 severity (a) and hospitalization status (b) among patients with psoriasis

\subsection{Predictors of COVID-19-Associated Hospitalization Among Patients with Psoriasis}

Table 2 demonstrates the findings of the univariate analysis, including all the variables that were found to be significantly associated with COVID-19-associated hospitalization. In a multivariable analysis, the following variables were found to independently predict COVID-19-associated hospitalization: older age ( $\geq 44.0$ years; adjusted OR $3.73 ; 95 \%$ CI $2.62-5.31 ; p<0.001)$, intake of methotrexate at the onset of the pandemic (adjusted OR 2.30; 95\% CI 1.11-4.78; $p=$ 0.025 ), cardiovascular diseases (adjusted OR 1.55; 95\% CI $1.12-2.16 ; p=0.009$ ), metabolic syndrome (adjusted OR 1.76; 95\% CI 1.31-2.36; $p<0.001$ ), COPD (adjusted OR 2.39; 95\% CI 1.52-3.77; $p<0.001$ ), and CRF (adjusted OR 2.93; 95\% CI 1.89-4.52; $p<0.001$; Table 2).

\subsection{Predictors of COVID-19-Associated Mortality Among Patients with Psoriasis}

Factors associated with COVID-19-associated mortality in univariate analysis are presented in Table 3. After adjusting for putative confounders, COVID-19-associated mortality was independently predicted by older age ( $\geq 44.0$ years; adjusted OR 11.23 ; 95\% CI 1.43-88.7339; $p=0.022$ ), cardiovascular diseases (adjusted OR 3.64; 95\% CI 1.77-7.50; $p<0.001$ ), metabolic syndrome (adjusted OR 2.90; 95\% CI 1.36-6.18; $p=0.006$ ), COPD (adjusted OR 2.24; 95\% CI $1.02-4.90 ; p=0.029$ ), and CRF (adjusted OR 3.47; 95\% CI 1.74-6.93; $p<0.001$; Table 3).

\section{Discussion}

The current population-based study revealed that the vast majority of patients with psoriasis who were COVID19-positive present with subclinical infection, whereas $10.5 \%$ and $1.6 \%$ of patients experience COVID-19-associated hospitalization and mortality, respectively. Older age, oral immunosuppressive agents, and comorbid cardiovascular diseases, metabolic syndrome, COPD, and CRF were found to independently predict COVID-19-associated hospitalization. COVID-19-associated mortality was independently predicted by older age and the aforementioned comorbidities.

Compelling evidence had accumulated to suggest that patients with psoriasis are at an increased risk of developing severe infections. Following 69,315 patients with psoriasis, Yiu et al. [24] found a 36\% increased risk of being hospitalized and a $33 \%$ increased risk of death because of serious infections among patients with psoriasis relative to matched controls. An earlier controlled retrospective cohort study tracked 25,742 patients with psoriasis and correspondingly found an increased risk of developing severe infections (adjusted hazard ratio 2.08; 95\% CI 1.96-2.22) [25]. Congruently, serious infections were found to develop more frequently in a cohort of 199,700 patients with psoriasis (adjusted hazard ratio 1.21 ; 95\% CI 1.18-2.23) [26]. The pathomechanism underlying increased infection rates is yet to be determined. However, it is established that the damage made by an infectious agent is determined both by the agent's ability to interfere with the homeostatic mechanisms of the host and by the host's response to the infectious agent [27]. The skew towards an excessive inflammatory cytokine milieu in psoriasis, particularly tumor necrosis factor- $\alpha$ and IL-17, may be implicated in the profound inflammation and tissue damage seen in bacterial and viral infections [28, 29]. Excessive levels of proinflammatory cytokines were found to result in dysregulation of the immune response and induce pathological inflammatory changes associated with septic shock [30].

The current study signifies that older age is associated with an increased risk of both hospitalization and mortality resulting from COVID-19 in patients with psoriasis. The latter finding aligns with a large body of data from patients with COVID-19, regardless of their inflammatory comorbidities [31]. While male individuals were predisposed to 
Table 2 Factors associated with COVID-19-associated hospitalization among patients with COVID-19-positive psoriasis

\begin{tabular}{|c|c|c|c|c|c|c|c|c|}
\hline & $\begin{array}{l}\text { Prevalence in } \\
\text { patients with } \\
\text { COVID-19-asso- } \\
\text { ciated hospitaliza- } \\
\text { tion, } n(\%) ;(N= \\
332)\end{array}$ & $\begin{array}{l}\text { Prevalence in } \\
\text { patients without } \\
\text { COVID-19-asso- } \\
\text { ciated hospitaliza- } \\
\text { tion, } n(\%) ;(N= \\
2819)\end{array}$ & Univariate OR & $\begin{array}{l}95 \% \\
\text { confidence } \\
\text { interval }\end{array}$ & $p$-value & Multivariate OR & $\begin{array}{l}95 \% \\
\text { confidence } \\
\text { interval }\end{array}$ & $p$-value \\
\hline $\begin{array}{l}\text { Age at the onset of } \\
\text { pandemic } \geq 44.0 \\
\text { years }^{\mathrm{a}}\end{array}$ & $284(85.5)$ & $1292(45.8)$ & 6.99 & $5.11-9.58$ & $<0.001$ & 3.73 & $2.62-5.31$ & $<0.001$ \\
\hline Male sex & $181(54.5)$ & 1314 (46.6) & 1.37 & $1.09-1.73$ & 0.006 & 1.11 & $0.86-1.46$ & 0.431 \\
\hline $\begin{array}{l}\text { Jewish ethnicity (vs } \\
\text { Arab ethnicity) }\end{array}$ & $245(73.8)$ & $2036(72.2)$ & 1.08 & $0.84-1.40$ & 0.545 & & & \\
\hline $\begin{array}{l}\text { Low SES (vs high } \\
\text { and intermediate) }\end{array}$ & $142(42.8)$ & $1274(45.2)$ & 0.91 & $0.72-1.14$ & 0.401 & & & \\
\hline $\begin{array}{l}\text { Duration of psoria- } \\
\text { sis at the onset of } \\
\text { pandemic } \geq 7.6 \\
\text { years }^{\mathrm{a}}\end{array}$ & $188(56.6)$ & $1381(49.0)$ & 1.36 & $1.08-1.71$ & 0.008 & & & \\
\hline $\begin{array}{l}\text { Moderate-to-severe } \\
\text { psoriasis (vs mild } \\
\text { psoriasis) }^{\mathrm{b}}\end{array}$ & 65 (19.6) & $374(13.3)$ & 1.59 & $1.19-2.13$ & 0.002 & & & \\
\hline Psoriatic arthritis & $139(20.2)$ & $569(20.2)$ & 2.85 & $2.25-3.61$ & $<0.001$ & 1.28 & $0.97-1.68$ & 0.073 \\
\hline Flexural psoriasis & $89(26.8)$ & $715(25.4)$ & 1.08 & $0.83-1.39$ & 0.568 & & & \\
\hline $\begin{array}{l}\text { Biologics at the } \\
\text { onset of pan- } \\
\text { demic }\end{array}$ & $6(1.8)$ & $68(2.4)$ & 0.75 & $0.32-1.73$ & 0.491 & & & \\
\hline $\begin{array}{l}\text { Cyclosporine at } \\
\text { the onset of } \\
\text { pandemic }^{b}\end{array}$ & $0(0.0)$ & $4(0.1)$ & 0.99 & $0.98-1.00$ & 0.492 & & & \\
\hline $\begin{array}{l}\text { Methotrexate at } \\
\text { the onset of } \\
\text { pandemic }^{b}\end{array}$ & $12(3.6)$ & $32(1.1)$ & 3.27 & $1.67-6.41$ & $<0.001$ & 2.30 & $1.11-4.78$ & 0.025 \\
\hline $\begin{array}{l}\text { Cardiovascular } \\
\text { diseases }\end{array}$ & $113(34.0)$ & $247(8.8)$ & 5.37 & $4.14-6.98$ & $<0.001$ & 1.55 & $1.12-2.16$ & 0.010 \\
\hline $\begin{array}{l}\text { Metabolic syn- } \\
\text { drome }\end{array}$ & $154(46.4)$ & 409 (14.5) & 5.10 & $4.01-6.48$ & $<0.001$ & 1.76 & $1.31-2.36$ & $<0.001$ \\
\hline COPD & $44(13.3)$ & $65(2.3)$ & 6.47 & 4.33-9.67 & $<0.001$ & 2.37 & $1.52-3.79$ & $<0.001$ \\
\hline Asthma & 37 (11.1) & $251(8.9)$ & 1.28 & $0.89-1.85$ & 0.180 & & & \\
\hline Smoking & $143(43.1)$ & $812(28.8)$ & 1.87 & $1.48-2.36$ & $<0.001$ & 0.95 & $0.72-1.27$ & 0.718 \\
\hline Cirrhosis $^{\mathrm{c}}$ & $3(0.9)$ & $5(0.2)$ & 5.13 & $1.22-21.57$ & 0.013 & & & \\
\hline $\begin{array}{l}\text { Chronic renal } \\
\text { failure }\end{array}$ & $54(16.3)$ & $62(2.2)$ & 8.64 & $5.88-12.70$ & $<0.001$ & 2.98 & $1.92-4.61$ & $<0.001$ \\
\hline Malignancy & $54(16.3)$ & $174(6.2)$ & 2.95 & $2.12-4.11$ & $<0.001$ & 1.31 & $0.90-1.87$ & 0.148 \\
\hline Depression & 39 (11.7) & $184(6.5)$ & 1.91 & $1.32-2.75$ & $<0.001$ & 0.92 & $0.62-1.38$ & 0.700 \\
\hline $\begin{array}{l}\text { A history of } \\
\text { tuberculosis }\end{array}$ & $3(0.9)$ & $6(0.2)$ & 4.28 & 1.06-17.14 & 0.026 & & & \\
\hline
\end{tabular}

Bold indicates significant values

COPD chronic obstructive pulmonary disease, COVID-19 coronavirus disease 2019, OR odds ratio, SES socioeconomic status

Only variables demonstrating $p<0.050$ in the univariate analysis were subject to inclusion in the multivariate logistic regression model

The onset of the pandemic was defined as the date of the first confirmed case of COVID-19 in Israel 27 February, 2020

${ }^{a}$ Dichotomy of this continuous variable was based on its median value

${ }^{b}$ Disease severity and intake of oral systemic agents at the onset of the pandemic were collapsed as a single variable in the regression model because of significant collinearity between the two variables

${ }^{c}$ Variables with cell sizes $<10$ by hospitalization and death status were collapsed to ensure sufficient power in the adjusted model 
Table 3 Factors associated with COVID-19-associated mortality among patients with COVID-19-positive psoriasis

\begin{tabular}{|c|c|c|c|c|c|c|c|c|}
\hline & $\begin{array}{l}\text { Prevalence in } \\
\text { patients with } \\
\text { COVID-19-as- } \\
\text { sociated death, } n \\
(\%) ;(N=51)\end{array}$ & $\begin{array}{l}\text { Prevalence in } \\
\text { patients without } \\
\text { COVID-19-as- } \\
\text { sociated death, } n \\
(\%) ;(N=3101)\end{array}$ & Univariate OR & $\begin{array}{l}95 \% \text { confidence } \\
\text { interval }\end{array}$ & $p$-value & Multivariate OR & $\begin{array}{l}95 \% \\
\text { confidence } \\
\text { interval }\end{array}$ & $p$-value \\
\hline $\begin{array}{l}\text { Age at the onset } \\
\text { of pandemic } \\
\geq 44.0 \text { years }^{\mathrm{a}}\end{array}$ & $49(98.0)$ & $1527(49.2)$ & 50.51 & $6.97-366.23$ & $<0.001$ & 11.23 & $1.43-88.33$ & 0.022 \\
\hline Male sex & $30(60.0)$ & $1465(47.2)$ & 1.68 & $0.95-2.96$ & 0.073 & & & \\
\hline $\begin{array}{l}\text { Jewish ethnic- } \\
\text { ity (vs Arab } \\
\text { ethnicity) }\end{array}$ & $41(82.0)$ & $2240(72.2)$ & 1.75 & $0.85-3.62$ & 0.125 & & & \\
\hline $\begin{array}{l}\text { Low SES (vs } \\
\text { high and inter- } \\
\text { mediate) }\end{array}$ & $25(50.0)$ & $1274(45.2)$ & 0.91 & $0.72-1.14$ & 0.401 & & & \\
\hline 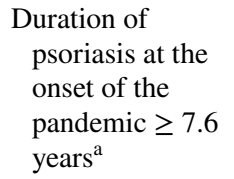 & $39(78.0)$ & $1530(49.3)$ & 3.64 & $1.86-7.13$ & $<0.001$ & & & \\
\hline $\begin{array}{l}\text { Moderate-to- } \\
\text { severe psoriasis } \\
\text { (vs mild pso- } \\
\text { riasis) }\end{array}$ & $13(26.0)$ & $426(13.7)$ & 2.21 & $1.16-4.19$ & 0.013 & 1.51 & $0.75-3.03$ & 0.245 \\
\hline Psoriatic arthritis & $28(56.0 \%)$ & $680(21.9 \%)$ & 4.53 & 2.57-7.97 & $<0.001$ & 1.35 & $0.73-2.49$ & 0.345 \\
\hline Flexural psoriasis & $15(30.0)$ & 789 (25.4) & 1.08 & $0.83-1.39$ & 0.463 & & & \\
\hline $\begin{array}{l}\text { Biologics at } \\
\text { the onset of } \\
\text { pandemic }\end{array}$ & $1(2.0)$ & $73(2.4)$ & 0.85 & $0.12-6.21$ & 0.870 & & & \\
\hline $\begin{array}{l}\text { Cyclosporine at } \\
\text { the onset of } \\
\text { pandemic }\end{array}$ & $0(0.0)$ & $4(0.1)$ & 0.99 & $0.98-1.00$ & 0.797 & & & \\
\hline $\begin{array}{l}\text { Methotrexate at } \\
\text { the onset of } \\
\text { pandemic }\end{array}$ & $1(2.0)$ & $43(1.4)$ & 1.42 & $0.19-10.53$ & 0.729 & & & \\
\hline $\begin{array}{l}\text { Cardiovascular } \\
\text { diseases }\end{array}$ & $34(68.0)$ & $328(10.5)$ & 18.09 & $9.88-33.13$ & $<0.001$ & 3.64 & 1.77-7.50 & $<0.001$ \\
\hline $\begin{array}{l}\text { Metabolic syn- } \\
\text { drome }\end{array}$ & $38(76.0)$ & $525(16.9)$ & 15.54 & $8.07-29.94$ & $<0.001$ & 2.90 & $1.36-6.18$ & 0.006 \\
\hline COPD & $12(24.0)$ & $97(3.1)$ & 9.78 & $4.96-19.30$ & $<0.001$ & 2.24 & $1.02-4.90$ & 0.029 \\
\hline Asthma & $6(12.0)$ & $282(9.1)$ & 1.36 & $0.58-3.23$ & 0.497 & & & \\
\hline Smoking & $26(52.0)$ & $929(30.0)$ & 2.53 & $1.45-4.44$ & 0.001 & 0.77 & $0.40-1.48$ & 0.433 \\
\hline Cirrhosis $^{\mathrm{b}}$ & $0(0.0)$ & $8(0.3)$ & 0.98 & $0.97-0.99$ & 0.719 & & & \\
\hline $\begin{array}{l}\text { Chronic renal } \\
\text { failure }\end{array}$ & $18(36.0)$ & $98(3.2)$ & 17.24 & $9.35-31.77$ & $<0.001$ & 3.47 & $1.74-6.93$ & $<0.001$ \\
\hline Malignancy & $9(18.0)$ & $219(7.1)$ & 2.89 & $1.39-6.02$ & 0.003 & 0.85 & $0.39-1.87$ & 0.685 \\
\hline Depression & $9(18.0)$ & $214(6.9)$ & 2.96 & $1.42-6.17$ & 0.002 & 1.26 & $0.57-2.75$ & 0.571 \\
\hline $\begin{array}{l}\text { A history of } \\
\text { tuberculosis }\end{array}$ & $1(2.0)$ & $8(0.3)$ & 7.89 & $0.97-64.30$ & 0.022 & & & \\
\hline
\end{tabular}

Bold indicates significant values

COPD chronic obstructive pulmonary disease, COVID-19 coronavirus disease 2019, OR odds ratio, SES socioeconomic status

Only variables demonstrating $p<0.050$ in the univariate analysis were subject to inclusion in the multivariate logistic regression model

The onset of the pandemic was defined as the date of the first confirmed case of COVID-19 in Israel 27 February 2020

${ }^{\text {a }}$ Dichotomy of this continuous variable was based on its median value. Age at the onset of pandemic and the duration of psoriasis were collapsed as a single variable in the regression model because of significant collinearity between the two variables

${ }^{\mathrm{b}}$ Categories with cell sizes $<10$ by hospitalization and death status were collapsed to ensure sufficient power in the adjusted model 
a more severe SARS-CoV-2 infection and worse COVID19 outcomes [31-33], we found that male sex predicted COVID-19-associated hospitalization in a univariate analysis but lost its statistical significance after adjusting for other covariates. In congruence with previous studies, comorbid cardiovascular and metabolic diseases, CRF, and COPD projected an increased risk of COVID-19-associated hospitalization and mortality [34-38]. Mortality rate among COVID-19-positive patients in the general Israeli population was estimated at $0.7 \%(6220 / 833,707$; as of 3 April, 2021). Mortality rate among patients with psoriasis tested positive for COVID-19 in the current study was $1.6 \%$. Taken together, mortality rate among patients with psoriasis in this study is higher than that among the general Israeli population $(p<0.001)$. Further controlled observational studies are warranted to establish this finding.

The role exerted by immunosuppressive and immunomodulatory drugs in COVID-19-infected patients is a focus of extensive debate [15]. Our findings denote that the intake of biologic agents did not predict COVID-19-associated hospitalization or mortality. Previous studies revealed favorable outcomes for patients with COVID-19 with underlying immune-related diseases managed by biologic agents. Tumor necrosis factor- $\alpha$ antagonists, in contrast to systemic corticosteroids, were found to decrease the risk of severe COVID-19-associated hospitalization and mortality among patients with inflammatory bowel diseases (OR, 0.60; 95\% CI 0.38-0.96) [11, 39]. Similarly, in a global registry of patients with rheumatic diseases and COVID-19, biologic agents were associated with a decreased risk of hospitalization (OR 0.46; 95\% CI 0.22-0.93) [5].

We found that patients taking oral methotrexate at the onset of COVID-19 were more frequently hospitalized and demonstrated worse clinical outcomes. The influence of methotrexate on the clinical outcomes of COVID-19 is less established. In a registry-based study, COVID-19-positive patients with rheumatic diseases did not demonstrate an increased risk of hospitalization under conventional synthetic disease-modifying antirheumatic drugs, including, among others, methotrexate [5]. Some experts even advocated utilizing the anti-inflammatory properties of methotrexate and cyclosporine to manage the cytokine storm in severe advanced SARS-CoV-2 infection [40, 41]. While caution should be practiced against causal inference about the effect of these drugs in COVID-19, a biological plausibility exists for our findings. Immunosuppressive drugs can be detrimental in the initial phase of the disease when the host immune response is essential to inhibit viral replication [15]. Methotrexate is typified by a broad and unspecific immunosuppressive effect that may render patients with psoriasis susceptible to infections [42].

The study throws light on a hot and unanswered question regarding predictors of COVID-19 complications in psoriasis. The strengths of the current study stem from the recruitment of a large-scale cohort of patients with psoriasis with inclusive access to their medical files. This enables a thorough identification of COVID-19 determinants in psoriasis. The diagnoses of psoriasis and COVID-19 are highly reliable as they relied on board-certified dermatologists and Food and Drug Administration-approved molecular tests, respectively. The inclusion of a wide array of comorbid diseases, medications, and disease-specific characteristics substantiates our model and facilitates a better overview of COVID-19 in psoriasis. The utilization of a comprehensive healthcare dataset encompassing patients belonging to all levels of healthcare facilities argues against the existence of selection bias. The current study has several limitations to acknowledge. Owing to the small number of hospitalized/dead patients with COVID19 with certain variables, we merged some variables (such as metabolic syndrome, cardiovascular diseases, biologic, and oral systemic drugs) to obtain meaningful findings. The probability of misclassification of disease severity and potential unmeasured confounding factors could not be thoroughly refuted. More specifically, the definition of moderate-to-severe disease based upon treatments may overlook patients in whom these drugs are contraindicated. While the large sample size and sufficient follow-up time render the current study generalizable, further studies assessing patients originating from different countries and ethnicities are warranted. The low number of patients with psoriasis under systemic and biologic drugs interferes with drawing firm conclusions and warrants the performance of studies with even larger sample sizes.

\section{Conclusions}

The current population-based study shows that COVID-19 necessitates hospitalizations in $10.5 \%$ and leads to death in $1.6 \%$ of COVID-19-positive patients with psoriasis. The intake of oral systemic immunosuppressive agents, but not biologics, at the onset of the pandemic predisposes patients with psoriasis to COVID-19-associated hospitalization. Older age, comorbid cardiovascular diseases, metabolic syndrome, COPD, and CRF independently predict COVID-19-associated hospitalization and mortality. The administration of immunosuppressive agents should be weighed with caution during the pandemic. Patients with psoriasis with comorbid cardiovascular diseases, metabolic syndrome, COPD, and CRF should be monitored closely.

Supplementary Information The online version contains supplementary material available at https://doi.org/10.1007/s40257-021-00605-8. 


\section{Declarations}

Funding Open access funding enabled and organized by Projekt DEAL. No sources of funding were received for the conduct of this study or the preparation of this article.

Conflict of interest Arnon D. Cohen served as an advisor, investigator, or speaker for Abbvie, BI, Dexcel Pharma, Janssen, Novartis, Perrigo, Pfizer, and Rafa. Khalaf Kridin, Yochai Schonmann, Dana Tzur Bitan, Giovanni Damiani, Alon Peretz, and Orly Weinstein have no conflicts of interest that are directly relevant to the content of this article.

Ethics approval The study was approved by the institutional review board in accordance with the Declaration of Helsinki (approval code: 0212-17-COM).

Consent to participate Not applicable.

Consent for publication Not applicable.

Code availability Not applicable

Availability of data and material The datasets generated during and/or analyzed during the current study are available from the corresponding author on reasonable request.

Author contributions $\mathrm{KK}$ and ADC had full access to all of the data in the study and take responsibility for the integrity of the data and the accuracy of the data analysis. Study concept and design: KK and ADC. Acquisition, analysis, and interpretation of data: KK, DTB, and AP. Drafting of the manuscript: KK and YS. Critical revision of the manuscript for important intellectual content: KK, ADC, and DTB. Statistical analysis: OW and YS. Obtained funding: None. Administrative, technical, or material support: ADC and OW. Study supervision: $\mathrm{KK}$ and ADC.

Open Access This article is licensed under a Creative Commons Attribution-NonCommercial 4.0 International License, which permits any non-commercial use, sharing, adaptation, distribution and reproduction in any medium or format, as long as you give appropriate credit to the original author(s) and the source, provide a link to the Creative Commons licence, and indicate if changes were made. The images or other third party material in this article are included in the article's Creative Commons licence, unless indicated otherwise in a credit line to the material. If material is not included in the article's Creative Commons licence and your intended use is not permitted by statutory regulation or exceeds the permitted use, you will need to obtain permission directly from the copyright holder. To view a copy of this licence, visit http://creativecommons.org/licenses/by-nc/4.0/.

\section{References}

1. Lake MA. What we know so far: COVID-19 current clinical knowledge and research. Clin Med (Lond). 2020;20(2):124-7.

2. Shi Y, Wang Y, Shao C, et al. COVID-19 infection: the perspectives on immune responses. Cell Death Differ. 2020;27:1451-4.

3. Vabret N, Britton GJ, Gruber C, Hegde S, Kim J, Kuksin M, Levantovsky R, Malle L, Moreira A, Park MD, Pia L, Risson E, Saffern M, Salomé B, Esai Selvan M, Spindler MP, Tan J, van der Heide V, Gregory JK, Alexandropoulos K, Bhardwaj N, Brown BD, Greenbaum B, Gümüş ZH, Homann D, Horowitz A,
Kamphorst AO, Curotto de Lafaille MA, Mehandru S, Merad M, Samstein RM; Sinai Immunology Review Project. Immunology of COVID-19: current state of the science. Immunity. 2020;52(6):910-41. https://doi.org/10.1016/j.immuni.2020.05. 002.

4. D'Silva KM, Serling-Boyd N, Wallwork R, et al. Clinical characteristics and outcomes of patients with coronavirus disease 2019 (COVID-19) and rheumatic disease: a comparative cohort study from a US hot spot. Ann Rheum Dis. 2020;79:1156-62.

5. Gianfrancesco M, Hyrich KL, Hyrich KL, et al. Characteristics associated with hospitalisation for COVID-19 in people with rheumatic disease: data from the COVID-19 Global Rheumatology Alliance physician-reported registry. Ann Rheum Dis. 2020;79:859-66.

6. Pablos JL, Galindo M, Carmona L, et al. Clinical outcomes of hospitalised patients with COVID-19 and chronic inflammatory and autoimmune rheumatic diseases: a multicentric matched cohort study. Ann Rheum Dis. 2020;79:1544-9.

7. Ansarin K, Taghizadieh A, Safiri S, et al. COVID-19 outcomes in patients with systemic autoimmune diseases treated with immunomodulatory drugs. Ann Rheum Dis. 2020. https://doi.org/10. 1136/annrheumdis-2020-218737.

8. Emmi G, Bettiol A, Mattioli I, Silvestri E, Di Scala G, Urban ML, Vaglio A, Prisco D. SARS-CoV-2 infection among patients with systemic autoimmune diseases. Autoimmun Rev. 2020;19(7):102575. https://doi.org/10.1016/j.autrev.2020.102575.

9. Fredi M, Cavazzana I, Moschetti L, et al. COVID-19 in patients with rheumatic diseases in northern Italy: a single-centre observational and case-control study. Lancet Rheumatol. 2020;2:e549-56.

10. Liu M, Gao Y, Zhang Y, et al. The association between severe or dead COVID-19 and autoimmune diseases: a systematic review and meta-analysis. J Infect. 2020;81:e93-5.

11. Macaluso FS, Orlando A. COVID-19 in patients with inflammatory bowel disease: a systematic review of clinical data. Digest Liver Dis. 2020;52:1222-7.

12. Armstrong AW, Read C. Pathophysiology, clinical presentation, and treatment of psoriasis: a review. JAMA. 2020;323:1945-60.

13. Parisi R, Iskandar IYK, Kontopantelis E, et al. National, regional, and worldwide epidemiology of psoriasis: systematic analysis and modelling study. BMJ. 2020;369:m1590.

14. Van den Bosch F, Coates L. Clinical management of psoriatic arthritis. Lancet. 2018;391:2285-94.

15. Schoot TS, Kerckhoffs APM, Hilbrands LB, et al. Immunosuppressive drugs and COVID-19: a review. Front Pharmacol. 2020;11:1333.

16. Russell B, Moss C, George G, Santaolalla A, Cope A, Papa S, Van Hemelrijck M. Associations between immune-suppressive and stimulating drugs and novel COVID-19-a systematic review of current evidence. Ecancermedicalscience. 2020;14:1022. https:// doi.org/10.3332/ecancer.2020.1022.

17. Gelfand JM, Armstrong AW, Bell S, et al. National Psoriasis Foundation COVID-19 Task Force guidance for management of psoriatic disease during the pandemic. Version 2: advances in psoriatic disease management, COVID-19 vaccines, and COVID19 treatments. J Am AcadDermatol. 2021;84:1254-68.

18. Talamonti M, Galluzzo M, Chiricozzi A, et al. Characteristic of chronic plaque psoriasis patients treated with biologics in Italy during the COVID-19 pandemic: risk analysis from the PSO-BIOCOVID observational study. Expert Opin Biol. 2021;21:271-7.

19. Mease PJ, Calabrese LH, Callis Duffin K, Haberman RH, Firmino R, Scher JU, Schick L, Winthrop K, Merola JF. Psoriasis and psoriatic arthritis in the context of the COVID-19 pandemic: a plenary session from the GRAPPA 2020 annual meeting. J Rheumatol. 2021; . https://doi.org/10.3899/jrheum.201671. 
20. Cohen AD, Dreiher J, Regev-Rosenberg S, et al. The quality indigators program in Clalit Health Services: the first decade. Harefuah. 2010;149:204-9.

21. Alberti KGMM, Zimmet PZ. Definition, diagnosis and classification of diabetes mellitus and its complications. Part 1: Diagnosis and classification of diabetes mellitus. Provisional report of a WHO consultation. Diabet Med. 1998;15:539-53.

22. Kridin K, Solomon A, Tzur-Bitan D, et al. Acne keloidalis nuchae and the metabolic syndrome: a population-based study. Am J ClinDermatol. 2020;21:733-9.

23. Third Report of the National Cholesterol Education Program (NCEP) Expert Panel on. 01-3670 2001.

24. Yiu ZZN, Parisi R, Lunt M, et al. Risk of hospitalization and death due to infection in people with psoriasis: a population-based cohort study using the Clinical Practice Research Datalink. Br J Dermatol. 2020;184:78-86.

25. Wakkee M, de Vries E, Van Den HP, et al. Increased risk of infectious disease requiring hospitalization among patients with psoriasis: a population-based cohort. J Am AcadDermatol. 2011;65(6):1135-44.

26. Takeshita J, Shin DB, Ogdie A, et al. Risk of serious infection, opportunistic infection, and herpes zoster among patients with psoriasis in the United Kingdom. J InvestigDermatol. 2018;138:1726-35.

27. Grondman I, Pirvu A, Riza A, et al. Biomarkers of inflammation and the etiology of sepsis. Biochem Soc Trans. 2020;48:1-4.

28. Bordon J, Aliberti S, Fernandez-Botran R, et al. Understanding the roles of cytokines and neutrophil activity and neutrophil apoptosis in the protective versus deleterious inflammatory response in pneumonia. Int J Infect Dis. 2013;17:e76-83.

29. Das S, Khader S. Yin and yang of interleukin-17 in host immunity to infection. F1000Res. 2017;6:741. https://doi.org/10.12688/ f1000research.10862.1.

30. Bosmann M, Ward PA. Therapeutic potential of targeting IL-17 and IL-23 in sepsis. ClinTransl Med. 2012;1(1):4.

31. Mallapaty $\mathrm{S}$. The coronavirus is most deadly if you are older and male: new data reveal the risks. Nature. 2020;585:16-7.
32. Haitao T, Vermunt JV, Abeykoon J, et al. COVID-19 and sex differences: mechanisms and biomarkers. Mayo Clin Proc. 2020;95:2189-203.

33. Pérez-López FR, Tajada M, Savirón-Cornudella R, et al. Coronavirus disease 2019 and gender-related mortality in European countries: a meta-analysis. Maturitas. 2020;141:59-62.

34. Goyal P, Choi JJ, Pinheiro LC, et al. Clinical characteristics of Covid-19 in New York City. N Engl J Med. 2020;382:2372-4.

35. Richardson S, Hirsch JS, Narasimhan M, et al. Presenting characteristics, comorbidities, and outcomes among 5700 patients hospitalized with COVID-19 in the New York City area. JAMA. 2020;323:2052-9.

36. Ruan Q, Yang K, Wang W, et al. Clinical predictors of mortality due to COVID-19 based on an analysis of data of 150 patients from Wuhan, China. Intensive Care Med. 2020;46:846-8.

37. Schultze A, Walker AJ, MacKenna B, et al. Risk of COVID-19-related death among patients with chronic obstructive pulmonary disease or asthma prescribed inhaled corticosteroids: an observational cohort study using the OpenSAFELY platform. Lancet Respir Med. 2020;8:1106-20.

38. Williamson EJ, Walker AJ, Bhaskaran K, et al. Factors associated with COVID-19-related death using OpenSAFELY. Nature. 2020;584:430-6.

39. Brenner EJ, Ungaro RC, Gearry RB, et al. Corticosteroids, but not TNF antagonists, are associated with adverse COVID-19 outcomes in patients with inflammatory bowel diseases: results from an international registry. Gastroenterology. 2020;159(481-91):e3.

40. Cure E, Kucuk A, Cumhur CM. Cyclosporine therapy in cytokine storm due to coronavirus disease 2019 (COVID-19). Rheumatol Int. 2020;40:1177-9.

41. Safavi F, Nath A. Silencing of immune activation with methotrexate in patients with COVID-19. J Neurol Sci. 2020;415:116942.

42. Dávila-Seijo P, Dauden E, Descalzo MA, et al. Infections in moderate to severe psoriasis patients treated with biological drugs compared to classic systemic drugs: findings from the BIOBADADERM Registry. J InvestigDermatol. 2017;137:313-21. 